\title{
LA CIUDADANÍA EN MIGUEL DE UNAMUNO: EL LIBRE EXAMEN Y LA PARTICIPACIÓN POLÍTICA ${ }^{1}$
}

\author{
Emanuel José Maroco dos Santos (USAL) ${ }^{2}$ \\ emanuel.ejms.santos@gmail.com
}

Resumen: Unamuno, a semejanza de los grandes clásicos del pensamiento occidental, es eternamente actual. Sus reflexiones sobre lo que ha de ser una democracia son a este propósito una expresión de la intemporalidad de su pensamiento político. Si es cierto que la cuestión sobre lo que es, e implica, la ciudadanía democrática motiva la reflexión de muchos filósofos actuales; no deja de ser igualmente cierto también que a ningún otro autor se debe la coherencia, llevada al límite, entre su idea de dicho concepto y su concreción en su vida civil. Unamuno - cual irascible "intelectual-político" que se ha desterrado voluntariamente en París por su enfrentamiento a la dictadura de Miguel Primo de Rivera, a la monarquía y al rey - es el ejemplo máximo de cómo deben ser entendidas y practicadas la democracia y la ciudadanía actuales en cuanto intervención política cimentada en el libre examen. Y es, precisamente, aquí donde la influencia del protestantismo liberal alemán tuvo un papel decisivo en su formación intelectual, sobre todo para un autor tan adepto de la herejía como deconstrucción de ortodoxias y dogmas que anulan el pensamiento individual en su libertad y autonomía.

Palabras clave: Miguel de Unamuno; España; ciudadanía; participación política y libre examen.

\section{INTRODUCGIÓN}

A la cuestión: ¿qué es una democracia?, todos sabemos

\footnotetext{
${ }^{1}$ Recebido: 20-11-2016/ Aceito: 16-01-2017/ Publicado on-line: 31-07-2017.

2 Emanuel José Maroco dos Santos é Doutor em filosofia pela Universidade de Salamanca, Salamanca, Espanha.
} 
aparentemente contestar afirmando ser el régimen político en el que el pueblo es el soberano. Sin embargo, a la hora de ir más allá de la mera definición tautológica, muy pocos ciudadanos, incluso algunos de nuestros licenciados, tienen presente que la misma sólo se mantiene a través del libre examen y de la participación política, esto es, a través de una ciudadanía consciente. Es por ello que revisitar a Unamuno hoy es comprender que el desfallecimiento de las democracias actuales - que son, como lo refiere y bien nuestro autor, el mejor régimen político de todos los otros posibles - radica en el desinterés por la res publica, por la cosa pública.

La inevitabilidad del pecado - o el humano como ser caído - para formularlo a la cristiana, por un lado, y la seducción del poder, por otro, hacen que la corrupción política sea algo inevitable. Es algo que es, fue y será siempre así, porque lo humano - recordemos la feliz expresión nietzscheana - es “demasiado humano". Pero el remedio para dicho problema no radica en la odiosa resignación, en que quedemos impasibles ante la misma por su inevitabilidad, sino y a contrario sensu en la lucha constante por la verdad y por el bien común. Y en esto Unamuno es un ejemplo a seguir. Pese el hecho de que no se haya afiliado a ningún partido político después de 1897 - año que señala su conocida crisis espiritual que dará origen al segundo período de su formación intelectual y subsiguientes - hizo de la participación política, en cuanto ensayista, novelista y periodista - pero sobre todo en cuanto periodista -, su sagrada misión de apostolado civil, como tanto gustaba de llamarle. Unamuno es un educador de su pueblo, es consabido, y en cuanto educador, sentía la necesidad de despertar a sus conciudadanos a los problemas de su país 
(Unamuno 1966, p. 1022). Por ello, escribió incansablemente sobre lo que era España, es decir, sobre su España ideal, intentando hacer que sus lectores con su acción política no permitiesen, en los políticos, la afirmación del bien particular sobre el bien colectivo.

Si hay algún aspecto de su pensamiento que nos permite comprender su concepción de ciudadanía ése es sin duda su concepción de pueblo español, nos referimos, claro, a su Volksgeist. Si el primer Unamuno - el Unamuno de los ensayos que componen su En torno al casticismo redactados en el año de 1895 -, cuando estaba en cuestión definir el progreso de la sociedad española, defendió la necesidad de europeización y de hispanización de la misma (Unamuno 1966, pp. 785-789), el Unamuno posterior a 1897, redefiniendo su toma de posición, defendió que el progreso de la sociedad española no debería ser realizado a partir de la europeización, que debería ser rechazada, en cuanto contranatural al espíritu del propio pueblo, sino a través del concepto de africanización (Unamuno 1968a, p. 926). La radicalización, como vemos, es máxima. Unamuno ya no habla de la necesidad de hispanizar a España, sino de africanizarla. El Unamuno moderado da lugar al Unamuno de los extremos.

Ahora bien, la cuestión que nos mueve no es saber si esta nueva actitud del rector salmantino, después de 1897, es correcta o incorrecta, sino la de saber cómo nuestro autor concebía la ipseidad cultural de su pueblo español para que a través de la misma podamos comprender su concepción de ciudadanía. Asumida esta metodología, nos cabe afirmar que, según don Miguel, varias son las razones por las cuales el espíritu del pueblo español era contrario al espíritu de los pueblos europeos. Según su informe, el Volksgeist 
nacional (1) era contrario al espíritu técnico y científico europeo, es decir, al positivismo y practicismo de finales del siglo XIX, que exhortan a la vida y a la ciencia, porque el espíritu del pueblo español, más cercano a la "vieja sabiduría africana" de san Agustín y Tertuliano, tendía a exhortar a los hombres para bien morir (Unamuno 1968a, p. 929), de ahí que no se haya cohibido de afirmar polémicamente “Que inventen ellos!” en una España lastrada por el analfabetismo y retraso cultural; (2) era también contrario a la Kultur alemana, a su ortodoxia racionalista y dogmática, ya que era a contrario sensu fundamentalmente herético y paradójico (Unamuno 1971, p. 991); y (3) era por último contrario al espíritu de pueblo francés, lógico y sensualista, porque el español era naturalmente pasional, configurándose a partir de sentimientos arbitrarios y extremos (Unamuno 1969b, p. 399).

Si se analiza con algún detalle la posición unamuniana hacia el positivismo, la kultur germánica y la estética francesa, vemos que nada de lo que afirma tiene desperdicio. Sostener que el espíritu español no es científico ni pragmático, que no es sensualista ni lógico, y que no es dogmático ni racionalista, es inmediatamente afirmar que el espíritu español es herético (Unamuno 1971, p. 982) y pasional (Unamuno 1968a, p. 935), en una palabra, formado por herejías (Unamuno 1971, p. 982), que se constituyen a partir de la afirmación alternativa o simultánea de los extremos (Unamuno 1966, p. 784), lo que implica la irrupción de la paradoja (Unamuno 1971, p. 982) en cuanto forma característica de decir, afirmar e investigar. ¿Qué significa esto en términos de estructuración y configuración de una democracia? En una palabra: que la ciudadanía, en cuanto hija de la herejía, debe ser entendida como expre- 
sión máxima de libertad espiritual y que la verdad en democracia radica en la afirmación de los extremos. Y, así definida lo que es una ciudadanía democrática, no podemos dejar de sentir una gran admiración por el pensamiento político unamuniano, ya que presenta una idea de democracia como participación política autónoma y libre de todos los ciudadanos que están llamados a participar democráticamente en el rumbo político, social, económico, ético y religioso de su país.

Que Unamuno utilice el concepto herejía no es fortuito ni casual y menos todavía ingenuo. La herejía es lo que se opone al dogma y lo desestructura. Y, claro, en democracias formadas a partir de partidos políticos, que representan siempre una parte del todo que es el país, ésta tiene la suma virtud de desestructurar los dogmas ideológicos, que, en su natural forma de ser, quieren imponerse a costa del debilitamiento de otras ideologías políticas que se le oponen y que son igualmente connaturales con el espíritu del propio pueblo. Asimismo, la herejía, en cuanto expresión máxima de la libertad de pensamiento, permite, pues, minimizar la fuerza política de los dogmas ideológicos. Pero el interés por el pensamiento político unamuniano no radica únicamente en el concepto de herejía, sino también, y con igual importancia, en su método filosófico, si se quiere político, el de la afirmación alternativa y simultánea de los extremos. Independientemente de la forma como Unamuno concibió la unión de los extremos, en el antes y en el después de su crisis espiritual del 97, nos parece claro que, ya sea concebida a partir del concepto de nimbo o de caleidoscopio (Morón Arroyo 2003, pp. 42-54) - siendo cierto que la naturaleza humana se estructura siempre a partir de ambas realidades -, la realidad política no podrá dejar de estructu- 
rarse a partir de los opuestos, de los partidos de derecha y de izquierda, lo cual implica que los mismos deben ser afirmados con igual intensidad y decisión, si se no se quiere sacrificar el todo a una de las partes.

En las líneas que siguen intentaremos interpretar el pensamiento de nuestro autor a partir de los conceptos de libre examen y de participación política. Pedimos al lector que se detenga a observar con algún detalle el cuadro teórico-conceptual unamuniano, ya que el mismo es particularmente sugestivo, por cuanto deja trasparecer el vínculo que el autor mantiene con el romanticismo, con el vitalismo y con el existencialismo a partir de su hondo personalismo, que lo obligó a dirigirse a una dimensión autobiográfica de la escritura.

\section{LA GIUDADANIA Y EL LIBRE EXAMEN}

Tal es mi profesión de fe de ciudadanía española - que se me da de honor -, sin rendirme a dogmas que excluyan herejías y aun negaciones. Desde muy joven frente a dogmas políticos, filosóficos y religiosos, he mantenido el principio liberal del libre examen, sin arredrarme en los lindes del escepticismo y del agnosticismo y haciendo de la rebusca la cura de la esperanza (Unamuno 1971, pp. 459-460).

Si hay algún aspecto del pensamiento de nuestro autor que recorre toda su obra éste es sin duda el del liberalismo. Sin embargo, durante la primera etapa de su formación intelectual (1882-1897), dicho tema ocupa tan sólo una pequeña parte de su pensamiento (1887-1890). De este modo, antes mismo de que analicemos los aspectos de su pensamiento filosófico que se conectan con la recepción de las ideas liberales, nos cumple percibir la estructura interna de su propio pensamiento político, sobre todo, durante la 
primera etapa de su formación personal, que culmina, como es bien sabido, con su crisis espiritual del 97, ya que su análisis nos permitirá comprender mejor su propuesta del libre examen como primer acto de ciudadanía. Para ello, pondremos especial énfasis en dos comentaristas de su pensamiento político. Nos referimos, en concreto, a Rivero Gómez y a Pérez de la Dehesa. Si, para el primer comentarista (Rivero Gómez 2008, pp. 165-179), la vida política del autor podría dividirse en cuatro períodos bien definidos, en virtud de su adhesión al fuerismo (-1882), al republicanismo federal (1882-1887), al liberalismo (18871890) y al socialismo (1890-1897); para el segundo (Pérez de la Dehesa 1973, pp. 58-66), este último período, el del socialismo, podría ser divido, aun, en dos etapas, la primera de fuerte adhesión al pensamiento marxista (1894-1896) y la segunda de alejamiento de dicho pensamiento (18961897).

Los motivos que han obrado en el alejamiento (año de 1890) y en el acercamiento (año de 1897) de Unamuno hacia el liberalismo son esencialmente dos: en primer lugar, la comprensión de que el liberalismo era la razón por la cual los patronos explotaban vilmente a sus obreros; y, después, la convicción de que los problemas de España eran más de carácter espiritual que material. En lo que concierne al tema, cabría subrayar, como pone de relieve Stephen Roberts, que, al contrario de lo que podría parecer, la crisis del 97 no supuso el rechazo absoluto de los ideales socialistas en su pensamiento posterior (Roberts 2007a, pp. 9192), ya que el socialismo continuará presente en su pensamiento después de dicha fecha. Pero con una diferencia fundamental, ya que compartirá su presencia con el liberalismo que alimentó a nuestro autor a partir de su lectura de 
los protestantes liberales alemanes. No nos extraña pues que, a partir del año de 1897, el pensamiento político unamuniano pasase a estructurarse a partir de un maridaje entre el socialismo y el liberalismo. Empero con preponderancia de este último, ya que el liberalismo terminó por constituirse como la piedra de toque a partir de la cual Unamuno analizó todos los problemas de su España ideal (Roberts 2007b, p. 148).

Como subraya con mucho acierto Victor Ouimette (1989, p. 69), las fuentes del liberalismo unamuniano no fueron tanto "las obras clásicas del liberalismo decimonónico" como "su herencia familiar" y su juventud vivida en Bilbao. Fue, por lo tanto, de una adhesión más sentimental que intelectual, ya que irrumpe, en su pensamiento, fundamentalmente, a partir de sus vivencias familiares y sociales, sólo más tarde corroboradas por la lectura de obras filosóficas, donde se destacan los protestantes liberales alemanes, de entre de los cuales podríamos señalar a Baur, a Strauss, a Schleiermacher, a Harnack y a Ritschl ${ }^{3}$ (Unamuno 1966, p. 760). En este aspecto, hay que subrayar que Unamuno no dejó de alabar la Reforma protestante y su principio liberal del libre examen, lo que le valió, entre otras cosas, luchas inflamadas con la Iglesia católica, mayormente con los jesuitas, a quienes les criticaba el principio ciego de la obediencia (Unamuno 1971, p. 1200). Con este cambio de perspectiva, es decir, con su toma de posición simultáneamente socialista y liberal, que caracteriza sus

\footnotetext{
${ }^{3}$ Nelson Orringer es un destacado intérprete de la obra de Miguel de Unamuno, a la misma dedicó un precioso estudio que intenta desvelar la influencia que los protestantes liberales alemanes han tenido en la formación del pensamiento religioso y político del insigne rector salmantino. Dicha obra es: Unamuno y los Protestantes Liberales (1902). Sobre las Fuentes de "Del sentimiento trágico de la vida”. Madrid: Gredos, 1985.
} 
etapas intelectuales posteriores a su crisis del 97, el pensamiento unamuniano pasará a vertebrarse a partir de ideales antropocéntricos que afirman el "valor individual de la persona” (Luján Palma 2009, p. 255). En esta interpretación, concordamos en lo esencial con Luján Palma, ya que el mayor cambio que evidencia la obra del autor es el paso de la conciencia colectiva a la conciencia individual. A lo antedicho, cabría añadir, tan sólo, en la línea de Stephen Roberts, que fue su liberalismo espiritual lo que permitió a Unamuno crear su España ideal (Roberts 2007b, pp. 147148).

En Unamuno, el liberalismo se estructura a partir de la noción de libertad espiritual, siendo, por ello, contrario a todo tipo de ortodoxia social, política o religiosa. Para el autor, lo decisivo consistía en la afirmación de herejías, ya que sólo a través de ellas el hombre podría ser verdaderamente libre. En este aspecto, Unamuno no dejó de acercarse al protestantismo liberal alemán y a su noción de libertad espiritual, ya que, para el bilbaíno, nada era más censurable que el deseo de educar a las nuevas generaciones según principios preestablecidos. Para Unamuno, el hombre era un fin en sí mismo y, por ello, un ser sumamente libre para poder autodeterminarse según sus propias convicciones. No nos extraña, pues, que en su artículo "De actualidad: pedagogía y milicia”, de 1921, hubiese escrito:

Hacer patriotas no es hacer fetichistas ni el culto a la patria es culto a trapos y chirimbolos. La idolatría es el peor vicio de la religión, lo mismo en el orden eclesiástico que en el civil. O sea, lo mismo en la religión del reino de Dios que en la del reino de la patria. O de la tierra (Unamuno 1921, Archivo CMU4).

\footnotetext{
4 Siempre que utilicemos la designación "Archivo CMU” en sustitución del número de página se Cont.
} 
Uno de los valores fundamentales de su liberalismo espiritual es el de la autonomía. Y en esto concuerda, en lo fundamental, con los ideales de la Ilustración francesa y alemana. En el ensayo "La señora no quiere libros", de 1915, Unamuno colocó en escena la aversión femenina hacia la lectura (Unamuno 1915, Archivo CMU). Nuestro autor, al analizar las razones de dicha aversión, verificó que éstas se clasificaban en tres grandes grupos: en el de las razones de orden afectivo, en el de las de orden económico y en el de las de orden religioso (Unamuno 1915, Archivo CMU). Dejando a un lado las dos primeras, creemos que merece la pena analizar los motivos de orden religioso, que, según Unamuno, llevaban a la población femenina a rechazar los libros. Para Unamuno, el hecho de que las mujeres sintiesen aversión hacia la lectura radicaba en la orientación espiritual de sus curas. Para don Miguel, el hecho de que los curas animasen a las mujeres a colocarse en contra de la lectura era algo manifiestamente pernicioso, dado que por este medio se limitaba su autonomía intelectual y espiritual, es decir, su capacidad de pensar y obrar según sus propios principios. Para Unamuno, ser libre es ser autónomo y ser autónomo es pensar, hablar y elegir por uno mismo. En lo que concierne al tema, cabría subrayar, también, que Unamuno, en el mencionado artículo, no se cohibió de burlarse de la censura hecha por los curas, en virtud de que éstos reprobasen "más lo herético que lo pornográfico" (Unamuno 1915, Archivo CMU). Y dicha bur-

debe al hecho de que dicho documento es un ensayo o artículo periodístico disperso que no se halla recogido en las Obras Completas del autor (Ed. Manuel García Blanco). Por otro lado, dado que los mismos han sido recogidos del periódico original sin referencia al número de página, no podemos, en cuanto comentaristas, sino hacer la referencia al Archivo de la Casa-Museo Unamuno de Salamanca donde dichos artículos se hallan recogidos. 
la tenía tanta más acritud cuanto que lo herético era sinónimo de herejías y, por lo tanto, de la libertad espiritual (Unamuno 1915, Archivo CMU).

(1) Hay que agregar otra aversión y esta es la más tenebrosa. Es la que el confesor les inculca. Ya sabrán mis lectores que hay un precio de quemadero, es decir, que se paga por ciertas obras - las de Víctor Hugo entre ellas, y esto delata la bobería de esas gentes - para quemar sus ejemplares (Unamuno 1915, Archivo CMU).

(2) Pedro - (AJosé) ¿Qué dices a eso de tu mujer?

José - ¡Bah!, hay que dejarle decir... y opinar... Soy decidido partidario de la libertad de pensamiento.

Raquel - ¿Hasta para la mujer?

José - Precisamente para la mujer... ¡Como no hay peligro...! A la gallina, libertad de volar.

Raquel - ¡Gracias, águila! (Unamuno 1968c, p. 530).

Para Unamuno, las herejías eran la mayor expresión de la libertad espiritual. Por ello, desde siempre, se ubicó en las antípodas de la ideocracia, término de construcción latina que creó para referirse a la tiranía de las ideas (Unamuno 1966, p. 954), porque, para nuestro autor, el uso de ideas preconcebidas, comúnmente aceptadas por todos, era el mayor símbolo de esclavitud espiritual (Unamuno 1966, p. 956). La radicalidad de su planteamiento surge cuando don Miguel, en las alas de la pura libertad espiritual, se opuso, incluso, a los principios filosóficos (1) de la "concordancia lógica de los conceptos" y (2) de la "adaequatio intellectus et rei” (Unamuno 1966, p. 954). Para Unamuno, el hombre era anterior a las ideas. Por ello creyó únicamente en la idea de hombre, ya que, a su juicio, ésta era la única "idea propulsora del progreso", esto es, porque sólo ésta era una "idea viva [y] encarnada" capaz de gozar, vivir, sufrir y morir (Unamuno 1966, pp. 954-955). A partir de este antropocentrismo vitalista, el concepto de verdad terminó por metamorfosearse en el concepto de verdad 
cordial, de tal forma que la verdad pasó a identificar lo que hace vivir, independientemente de su correcta adecuación mental o material (Unamuno 1966, p. 958). No nos extraña, pues, que Unamuno, en el artículo “La ideocracia”, de 1900, considerase que el mayor derecho que todos españoles deberían tener era el de la contradicción.

Entre todos los derechos íntimos que tenemos que conquistar, no tanto de las leyes cuanto de las costumbres, no es el menos preciso el inalienable derecho a contradecirme, a ser cada día nuevo, sin dejar por ello de ser el mismo siempre, a afirmar mis distintos aspectos trabajando para que mi vida los integre. Suelo encontrar más compactos, más iguales y más coherentes en su complejidad a los escritores paradójicos y contradictorios que a los que se pasan la vida haciendo de inconmovibles apóstoles de una sola doctrina, esclavos de una idea (Unamuno 1966, p. 956).

En Unamuno, la digestión de ideas y el canibalismo espiritual constituyen las dos formas autorizadas de apropiación de ideas. Para don Miguel, habría que evitar lo más posible la esclavitud ideológica. Para ello, cada individuo, en vez de dejarse esclavizar por sus propias ideas, debería buscar sacar lo más importante de ellas con vistas a construir y alimentar sus propios pensamientos. Y, para Unamuno, ésta era la única actitud vitalista de acercamiento a la vida, siempre cambiante y difusa (Unamuno 1966, p. 955). De este modo, si la digestión de ideas constituía la condición de posibilidad de destruir todas las ideas o ideologías de carácter dogmático, tan contrarias a la propia esencia de la vida humana (Unamuno 1968c, p. 1054), el canibalismo espiritual constituía, a su vez, la condición de la posibilidad de que cada individuo se alimentase del alma de sus semejantes (Unamuno 1968c, p. 1054).

Si nos es permitido valorar el pensamiento de Unamuno en lo que respecta a su propuesta del libre examen 
como primer acto democrático y de ciudadanía no podemos sino prestar adhesión intelectual completa a nuestro autor. Para nosotros, así como para Unamuno, la democracia, y la ciudadanía de que ella deriva, sólo es pensable a partir del concepto de libertad, ya que no cohabitan las democracias con la represión de los ciudadanos. Para defender dicha toma de posición, Unamuno, colocándose en las antípodas del principio de obediencia de los jesuitas, que criticó incansablemente a lo largo de su producción ensayística, aceptó sin reservas el principio liberal del libre examen. Apoyado en los pensadores más importantes del protestantismo liberal alemán, alabó la herejía hija de la libertad en detrimento del dogma primo derecho de la esclavitud intelectual. Aquí, el concepto de herejía, que deriva de herético y de hereje, maximiza, radicalizando, el pensamiento unamuniano. Sin que deseemos valorar su utilización de forma positiva o negativa, nos parece ineludible que su utilización implica una ruptura total con lo preestablecido. Y dicha toma de posición se hace más comprensible si se ubica en la España de finales del siglo XIX y principios del XX, completamente estructurada a partir de los valores de la Iglesia católica. Pero una cosa es cierta, Unamuno nunca quiso implantar, por lo menos que tengamos conocimiento, el protestantismo en su España finisecular. Y, si no lo quiso hacer, el concepto de herejía debe ser tomado en sentido figurado como defensa de ideas opuestas a las generalmente admitidas. Y si se define así el concepto de herejía en su obra y pensamiento tenemos que admitir que lo que Unamuno quiso fue, ante y sobre todo, libertad de conciencia.

La radicalización de su pensamiento surge cuando defiende la libertad por encima de los principios lógicos de la 
(1) concordancia lógica de los conceptos y (2) de la concordancia entre la conciencia y la realidad exterior a partir de la distinción entre verdad lógica y verdad cordial. Y, aquí, es necesario observar que don Miguel es un autor existencialista fuertemente influenciado por el romanticismo y por el vitalismo finiseculares. $\mathrm{Y}$ analizado su pensamiento desde estos supuestos, verificamos que lo que Unamuno postula es la afirmación del hombre y de la vida humana por encima de cualquier concepto o dogma lógico-abstracto. Siendo el hombre más importante que las ideas, Unamuno apela al sagrado derecho de contradecirse. Pero, ¿qué querrá significar dicha toma de posición unamuniana? En un primer momento, no es sencillo de entender, porque decir simultáneamente que algo es blanco y negro no es fácilmente admisible. Empero si se tiene en consideración su método filosófico, el de la afirmación alternada y simultánea de los contradictorios, se percibirá fácilmente que la contradicción a que Unamuno apela es a la condición de posibilidad de afirmar lo humano, cuya naturaleza es igualmente escindida y contradictoria. Y es justamente aquí que la herejía, desestructurando el dogma, permite no ya la destrucción del mismo, sino, y con mayor relieve, la afirmación de lo humano, que se ubica entre el tiempo y la eternidad, entre la gnosis y la pistis, entre la interioridad y la exterioridad, y en la política, entre el socialismo y el liberalismo, para enfocarlo unamunianamente. Coronan su antropocentrismo vitalista sus conceptos de digestión de ideas y de canibalismo espiritual. Siendo lo humano lo principal y lo cardinal, lo decisivo no son las ideas sino los pensamientos, y de serlo así lo que hay que hacer es digerir las ideas que nos habitan para hacer de ellas carne y hueso de nuestros espíritus. No nos extraña, pues, que 
Unamuno exhorte a sus lectores al canibalismo espiritual, a comerse espiritualmente a nuestro prójimo, lo que es tanto más significativo cuanto que el hombre es un ser inconcluso en tarea de hacerse a sí mismo con los otros. Y leído de este modo el pensamiento político unamuniano es imposible que el lector no se familiarice con él, apropiándose del mismo.

Veamos a continuación su concepto de participación política.

\section{LA GIUDADANÍA Y LA PARTICIPACIÓN POLÍTICA}

Sí, yo hago política y la hace todo el que manifiesta públicamente su opinión sobre un problema público. Y para ser político no es menester alistarse en ninguno de los partidos organizados, con mote, bandera y santo y seña, aunque no se me ocurra censurar a los que en ellos se alisten (Unamuno 1968c, p. 1033).

Directamente correlacionado con el tema de la libertad de pensamiento surge, en el autor, el de la participación política. Y dicho tema es tanto más importante cuanto que recorre todo su pensamiento, desde el inicio hasta el fin de su actividad intelectual, hallándose cristalizado, de forma bien explícita, en su ensayo "Los antipolicistas", de 1910, donde Unamuno criticó con vehemencia a todos los ciudadanos que afirmaban no participar en la vida pública. La razón de dicha agria toma de posición radicaba en la honda convicción de nuestro autor de que la política está detrás de todo el desarrollo social, político, económico y religioso de los Estados. Y dicho supuesto teórico era de tal forma asumido por Unamuno que nuestro autor no lo dejó de subrayar a partir de su interpretación del origen de la grandeza de Atenas y de toda Grecia. Para Unamuno, fue la política, entendida como ciudadanía o como participación pública 
de todos los ciudadanos, la causa de la grandeza de "la filosofía de Platón, de la lírica de Píndaro, de la tragedia de Esquilo, de la historia de Tucídides [...] [y] de la elocuencia de Demóstenes" (Unamuno 1968a, p. 492). No nos extraña, pues, que don Miguel considerase que donde se desvanecía el interés por la política decaía, de forma inexorable, el desarrollo científico, artístico e industrial de los Estados.

Una de las cosas que más me han llamado la atención durante mi estancia en Canarias es la frecuencia y el tono con que varios me hacían esta advertencia: "Bueno; debo advertirle a usted que yo no soy político". Decíanlo como defendiéndose de alguna acusación tácita o como recomendándose a mi aprecio. A cada paso oía decir de alguno: “¿Ese? ¡Ese es un político!”. Se habla allí en general de los políticos como de una especie aparte o como de hombres que se dedican a una profesión vitanda. Y son muchos, muchísimos, los que se jactan de su indiferencia respecto a la política. Y éste me parece que es uno de los más graves males de aquel país hermosísimo y no todo lo venturoso que merece ser (Unamuno 1968a, p. 489).

A partir de estos supuestos, Unamuno distinguió, en su ensayo "Los profesionales de la política", de 1914, dos tipos de políticos: los religiosos y los irreligiosos (Unamuno 1971, p. 1220). Para el catedrático de Salamanca, eran políticos irreligiosos todos los que estimaban que su función política no era más que ganar las elecciones, y que las ideas o doctrinas políticas que profesaban no tenían otro objetivo que el de "ganar y acrecentar votos" (Unamuno 1968c, p. 1033). En las antípodas de dicha concepción, Unamuno sostuvo que los políticos religiosos eran, por lo contrario, todos los que se proponían "fraguar conciencia colectiva" (Unamuno 1968c, p. 1064), esto es, todos los que se alejaban del deseo de poder (Unamuno 1971, p. 1220), confiriendo a su acción política una conciencia moral 
(Unamuno 1966, p. 1105). En lo que concierne al tema, es muy sugestiva la distinción que el autor hizo en su ensayo "Estética política", de 1916, entre las dos formas posibles de hacer política. Nos referimos, en concreto, a los conceptos de estética positiva y de estética negativa. Para Unamuno, la estética negativa representaba toda acción política en la que las palabras no eran más que pura palabrería (Unamuno 1968c, p. 1086), es decir, que se perdían en puras formas verbales alejadas de todo el contenido político, mientras que la estética positiva era lo que se refería a todo acto político donde las palabras no eran una mera oquedad sino palabras llenas de contenido y significado político (Unamuno 1968c, p. 1087).

La concepción unamuniana de política manifiesta un claro acercamiento a la raíz etimológica del vocablo, donde

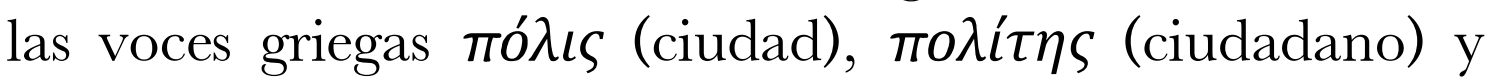

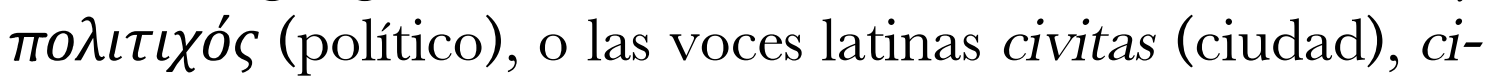
vis (ciudadano) y civilitas (ciudadanía) participan todas de la misma raíz semántica. De este modo, la política, en Unamuno, no se refiere tan sólo a los políticos profesionales, sino también a todos los ciudadanos y a la forma como éstos plantean y solucionan los problemas públicos de su país. Para Unamuno, si se tiene en consideración su ensayo "Los antipolicistas", de 1910, el concepto de política era extensible a todos los problemas sociales o, en sus palabras, a todas las grandes cuestiones humanas como las de orden económico, religioso, sanitario o cultural (Unamuno 1968c, p. 492). Con dicha concepción, que abarca todos los temas sociales, así como a todos los ciudadanos electores, Unamuno se acercó, inevitablemente, a la noción de democracia. Y quizás sea ésta su propuesta filosófica más relevante para su España de finales del siglo XIX y princi- 
pios del XX, donde las altas tasas de analfabetismo constituían el mayor hándicap para su concreción. No nos extraña, pues, su aversión a todos los ciudadanos que se consideraban "neutros" (Unamuno 1968a, p. 489), esto es, a los que no se consideraban políticos, ya que, en la vida pública, todos son políticos, es decir, todos deben ser ciudadanos comprometidos con la realidad política, social y económica de su país.

No me entusiasman grandemente las democracias, pero hoy son ya inevitables. La democracia es acaso, como la guerra y tal vez la civilización misma - ¡y quién sabe si la vida!...-, un mal necesario. Hay que aceptarlas o sucumbir. Y la democracia nos impone más obligaciones y deberes que nos confiere privilegios y derechos. Y el primer deber que la democracia nos impone es el de interesarnos en el manejo de la cosa pública, de la res publica (Unamuno 1968a, p. 489).

Para Unamuno, el pueblo constituye la base de la política democrática. No nos extraña, pues, que, a su juicio, éste debiese "querer ser soberano", esto es, debiese querer darse a sí mismo las leyes que lo rigen (Unamuno 1916, Archivo CMU), ya que sólo así podía ser verdaderamente libre (Unamuno 2003, p. 417). Fue por ello que creyó que lo que había de más perverso en su España finisecular era el desinterés político del propio pueblo; desinterés que permitía, a su juicio, que los poderes pretorianos y gubernamentales entrasen reiteradamente en conflicto (Unamuno 2003, p. 417). Precisamente por ello, Unamuno, en su ensayo "Los profesionales de la política", de 1914, bromeó con el acto electoral, afirmando que éste no es más que una ficción, en la medida en que el mismo demostraba que el pueblo no era libre, esto es, que no tenía conciencia de su realidad e importancia (Unamuno 1916, Archivo CMU).

- ¡Pero hay que hacer elecciones!... 
-Sin duda, y como el pueblo no las hace, como no vota ni puede votar libremente, porque la libertad implica conciencia, la libertad no es sino conciencia, la libertad en un ser es la conciencia de la ley por que se rige; como el pueblo no vota, hacéis ficción vosotros, los profesionales de la política. Y os cuidaréis mucho de hacer conciencia pública, porque eso sería vuestra muerte (Unamuno 1968c, p. 1035).

El Unamuno político, es decir, el Unamuno comprometido con la realidad política y social de su país, es un modelo de participación política que nos cabe igualmente analizar. Para ello, nos ceñiremos fundamentalmente a su conferencia Palabras de agradecimiento al ser nombrado ciudadano de honor de la República, de 1935. En dicho discurso nuestro autor se refirió a un conjunto de datos biográficos a través de los cuales quiso poner de relieve su ciudadanía o, si se quiere, su interés por la res publica. El primer dato que el autor mencionó se refirió a su nombramiento como rector de la Universidad de Salamanca. En dicho nombramiento, nuestro autor quiso hacer patente que el mismo no supuso ninguna "adhesión doctrinal" o "declaración monárquica” (Unamuno 1971, p. 458), lo que evidencia, a su juicio, y al nuestro, su libertad y autonomía intelectuales. El segundo dato biográfico que indicó fue el de su destitución como rector de la Universidad de Salamanca, que coincidió con el inicio de la Primera Guerra Mundial. Pese al hecho de que nuestro autor no hubiese revelado, en dicha ocasión, la discordia que mantuvo con el conde de Romanones, no ha dejado de afirmar que su relación polémica con la causa germánica, con la monarquía y con el rey fue lo que desencadenó la referida destitución (Unamuno 1971, pp. 458-459). El tercer dato biográfico se refirió al año de 1924, año en que Unamuno fue confinado en la isla de Fuerteventura, a consecuencia de su oposición 
a la dictadura de Primo de Rivera (Unamuno 1971, p. 459). El cuarto fue el de su exilio voluntario en París, donde hostigó, como ningún otro español, a la dictadura y al monarca (Unamuno 1971, p. 459). Y el quinto fue el de su regreso a España y consecuente proclamación de la República desde la Plaza Mayor de Salamanca (Unamuno 1971, p. 459). Cabría subrayar, también, que, en el mismo año de 1931, Unamuno fue elegido diputado liberal republicano en las Cortes Constituyentes. Pero esta elección, al igual que su nombramiento como rector, no implicó de su parte ninguna adhesión intelectual o partidaria (Unamuno 1971, p. 459). A este propósito, no quisiéramos cerrar el presente apartado sin dejar de trascribir un fragmento del discurso que pronunció en las Cortes de la República, el 25 de septiembre de 1931, ya que, en el mismo, nuestro autor afirmó tajantemente ser diputado español independientemente de cualquier contingencia política:

Yo no he estado nunca en ningún partido, no me ha traído aquí ningún partido político; no me ha traído aquí Castilla ni Salamanca. Yo no soy un diputado de Castilla, ni siquiera en rigor creo que me ha traído aquí la República, aunque sea hoy un diputado republicano. Aquí me ha traído España; yo me considero como un diputado de España; no un diputado de un partido, no un diputado castellano, no un diputado republicano, sino un diputado español (Unamuno 1971, p. 394).

Es imposible que quedemos indiferentes a los conceptos íntimamente interconectados de político y de participación política de Unamuno. Si hay sinceridad intelectual estamos forzados a admitir que dichos conceptos están categóricamente bien dibujados por nuestro autor. Decir como Unamuno dice que el político es el ciudadano común y no solo los ciudadanos que componen los partidos políticos y que a raíz de dicho hecho cada político, esto es, cada ciudadano, 
debe estar comprometido con la realidad social, económica, religiosa, sanitaria y cultural de su país - con la res publica - es asentar los cimientos de una democracia en el verdadero sentido de la palabra.

Para Unamuno, el pueblo debería "ser el guía de su propio destino" (Gómez de la Torre 2000, p. 21). Para ello, debería involucrarse con los problemas de su país. No nos extraña, pues, que se indignase con los llamados "neutros", con aquellos para quienes los problemas de la patria no les importaban. Pero, hay un sentido más hondo en las afirmaciones unamunianas de que el pueblo es el cimiento de la política democrática y de que los actos electorales de su época histórica no eran más que pura ficción. Y hay un sentido más hondo - decíamos - porque para que el pueblo sea el soberano de sí mismo, es decir, se dé a sí mismo las leyes que lo rigen, tiene que poseer un elevado nivel de ilustración, ya que si no la tiene no podrá votar conscientemente en las propuestas políticas que le presentan. Unamuno lo vio claramente en su época, y nos ha alertado sobre ello, diciendo que hay que educar al pueblo analfabeto. Lo que cabe preguntar, pues, es si hoy día con la erradicación del analfabetismo puede el pueblo ser soberano en el sentido genuino de la palabra. Basta ver cómo se realizan las elecciones y la propaganda electoral para ver que no. El pueblo no tiene conocimientos básicos ni de economía, ni de política, ni de ética y por ello no está capacitado para valorar conscientemente los programas partidarios. Don Miguel, teniendo plena conciencia de ello, propuso como asignatura de la formación general de los alumnos de la enseñanza secundaria la de economía política (Unamuno 1971, p. 140) y justo es afirmar que su propuesta educativa tiene máximo interés en nuestra época, pues si se quiere 
una democracia en el verdadero sentido de la palabra los ciudadanos deberán (1) poseer necesariamente conocimientos de macro- y microeconomía, (2) de conocer la génesis y la esencia de las diversas familias políticas y la forma como está organizado el Estado, así como (3) de comprender las diferentes fuentes del pensamiento ético contemporáneo. Y si esto es así podemos decir, como Unamuno lo ha dicho en su época, que el pueblo no es todavía soberano y que las elecciones no pasan de una pura ficción incluso en nuestras propias democracias. ¿Qué podrá hacerse para cambiar este estado de cosas, para que el pueblo pueda ser efectivamente "el guía de su destino"? La respuesta nos parece sencilla: hacer que sean asignaturas obligatorias de nuestros institutos de segunda enseñanza las de economía, de política y de ética, pues sólo de este modo podrá el pueblo adquirir aquel conjunto de conocimientos esenciales para una ciudadanía consciente. El sueño de una Ágora ateniense no puede morir entre nosotros, ni el pueblo puede continuar siendo entontecido con novelas y programas del corazón. Es necesario que el pueblo sea soberano, que haya democracias, pero no de ficción, donde se pelean a mordiscos los políticos en la búsqueda del ansiado poder. Aquí la distinción unamuniana entre políticos irreligiosos y religiosos es fundamental, ya que el verdadero político es el que "hace [...] opinión pública, [esto es,] [es el que] fragua [...] la consciencia colectiva" (UNAMUNO 1968c, p. 1064). Hacer que nuestros Estados sean democracias en el pleno sentido de la palabra es lo que a todos nos atañe.

\section{SINOPSIS DEL ARTÍ́CULO}

En definitiva, en términos políticos, Unamuno fue el má- 
ximo defensor de la libertad espiritual. Con su defensa, el autor se opuso, de forma directa e inmediata, a toda clase de dogmatismos y totalitarismos religiosos, ideológicos o políticos, exhortando a todos sus conciudadanos a la herejía y a la contradicción. Con dicha exhortación, Unamuno no hirió el concepto de verdad, dado que su existencialismo vitalista reconoce dos tipos de verdad: la lógica y la cordial. Unamuno, al minimizar la importancia de la primera, concibió la segunda en términos eminentemente vitalistas, de tal forma que creyó ser verdadero todo lo que fuese señal de vida. Coronan su pensamiento los conceptos digestión de ideas y canibalismo espiritual. Si por el primero cada individuo debería liberarse de la esclavitud de sus ideas, recogiendo de ellas, tan sólo, lo que le permitía aumentar y ensanchar su propia vida, por el segundo cada individuo podría enriquecer su espíritu, alimentándose del alma de sus semejantes. Por otro lado, en Unamuno, la defensa de la libertad de pensamiento tiene, también, como finalidad la exhortación a la participación en la vida pública. Lo fundamental era que la sociedad española finisecular fuese consciente de sus problemas económicos, políticos y religiosos, y buscase la solución de los mismos en la plaza pública. En este aspecto, cabría subrayar que Unamuno identificó el concepto de político con el de ciudadano, intentando convertir la sociedad española en una gran democracia, donde todos deberían tener el derecho y el deber de participar. A este propósito, su accidentada vida política podría presentarse como un ejemplo de participación pública y de compromiso político, que todos los españoles deberían intentar imitar, tanto más cuanto que don Miguel colocó el interés político nacional por encima de sus propios intereses particulares, como bien lo demuestra su exilio voluntario. Y en 
lo que concierne a los políticos profesionales, Unamuno no dejó de criticar a todos aquellos que asumían la vida política como un medio para sus propios intereses particulares o del partido. Con ello, revistió la política de un carácter ético-religioso, en la medida en que la misma sólo sería verdaderamente digna si estuviese subordinada al interés común, a todos los españoles, esto es, a España.

\section{CONCLUSIONES}

No quisiéramos terminar este estudio sobre el pensamiento político de Unamuno sin hacer una breve referencia, a guisa de conclusión, a la participación política de nuestro autor. De entre los inmensos datos a los cuales nos podríamos referir quisiéramos mencionar los siguientes: primero, su nombramiento como rector de la Universidad de Salamanca en el año de 1900; después, su polémica con el obispo Cámara en 1904; seguidamente, su destitución como rector en el año de 1914; a continuación, su exilio voluntario en 1924; y, por último, la proclamación de la República en el año de 1931.

$\mathrm{El}$ hecho de que deseemos mencionar dichos datos, casi todos ya descritos en el presente artículo, radica en el hecho de que consideremos a Unamuno como el ciudadano político por excelencia. Primeramente, porque sólo aceptó su nombramiento como rector de la Universidad del Tormes porque el mismo no implicaba "adhesión doctrinal" o "declaración monárquica”, lo cual quiere decir que nunca quiso abdicar de su sagrado derecho a la libertad intelectual. En segundo lugar, porque no se cohibió de enfrentarse al obispo Cámara con sus posicionamientos religiosos hasta el punto de plantear la posibilidad de retirarse con los suyos 
en Argentina para "escapar del ambiente agobiante de la pequeña ciudad del Tormes" (Raut 2004, p. 14). Después, porque al no implicarse en la elección de senador por la Universidad de Salamanca, cargo que consideraba ajeno a la maestría universitaria, acabó por ser destituido como rector (García Blanco 1963, p. 21). En cuarto lugar, porque no pudiendo dejar de oponerse a regímenes dictatoriales tuvo que exilarse en Francia lejos de los suyos enfrentándose desde el otro lado de la frontera con los opresores del pueblo español. Y, finalmente, porque fue nuestro autor quien proclamó la República desde la Plaza Mayor de Salamanca. Y mirados de este modo sus actos de ciudadanía no podemos dejar de contemplar al ciudadano político Unamuno como un ejemplo máximo de ciudadanía democrática. Y es con la invocación de sus actos más importantes de ciudadano comprometido con los problemas de su país que cerramos el presente estudio, sintiendo honda admiración por el "intelectual-político" Unamuno, cuyo ejemplo debería ser imitado por todos los académicos y por todos los ciudadanos en general, es decir, por todos los que posean conocimientos mínimos de cultura general que les permitan ser un motor del progreso social, económico y político en su pueblo, villa o ciudad.

Abstract: Unamuno, like all the great classic Western thinkers, is eternally relevant to the present time. His reflections concerning what a democracy should be are in this sense an expression of the timelessness of his political thought. Certainly, the question of what democratic citizenship is and involves is motivating the thinking of many of today's philosophers; it is also no less certain that no other author has been so consistent in taking to the limit the relation between the idea of that concept and its implementation in his civic life. Unamuno - as an irascible "intellectual-politician" in self-exile in Paris owing to his confrontation with the Miguel Primo de Rivera dictatorship, the monarchy and the king - is the highest example of how current democracy and citizenship should be understood and practised in terms of political intervention established on free examination of conscience. And it is 
precisely here where the influence of German liberal Protestantism played as decisive role in his intellectual formation, especially for an author so adept in heresy as deconstruction of orthodoxies and dogmas that disallow individual thought in its freedom and autonomy.

Keywords: Miguel de Unamuno; Spain; citizenship; political participation and free examination.

\section{REFERENGIAS}

\section{FUENTES}

Unamuno, M. Artículos desconocidos en "El Mercantil Valenciano" (1917-1923). Valencia: Biblioteca Valenciana, 2003.

- Comentario. In: El Día Gráfico, Madrid, 15.XII.1916. Archivo Casa Museo Unamuno.

. De actualidad: pedagogía y milicia. In: El Liberal, Madrid, 12.I.1921. Archivo Casa Museo Unamuno.

. La señora no quiere libros. In: El Día Gráfico, Barcelona, 4.I.1915. Archivo Casa Museo Unamuno.

. Obras completas I. Madrid: Escelicer, 1966.

. Obras completas II. Madrid: Escelicer, 1967.

. Obras completas III. Madrid: Escelicer, 1968a.

. Obras completas IV. Madrid: Escelicer, 1968b.

. Obras completas $V$. Madrid: Escelicer, 1968c.

. Obras completas VI. Madrid: Escelicer, 1969a.

. Obras completas VII. Madrid: Escelicer, $1969 \mathrm{~b}$. 
. Obras completas VIII. Madrid: Escelicer, 1970.

. Obras completas IX. Madrid: Escelicer, 1971.

\section{INVESTIGACIONES}

Abellán-García, J. L. Sociología del noventa y ocho: un acercamiento a su significado. Madrid: Biblioteca Nueva: 1997.

Álvarez Gómez, M. Unamuno y Ortega: la búsqueda azarosa de la verdad. Madrid: Biblioteca Nueva, 2003.

Aubert, P. Miguel de Unamuno y la política: de la predicación cívica a la disidencia. In: Chaguaceda Toledano, A. (ed.). Miguel de Unamuno. Estudios sobre su obra II. Salamanca: Ediciones Universidad de Salamanca, 2005, pp. 213-235.

Azaola, J. M. Unamuno y sus guerras civiles. Bilbao: Ediciones Laga, 1996.

Béracoud, J. Miguel de Unamuno y la Segunda República. Madrid: Taurus, 1965.

Blanco Aguinaga, C. El socialismo de Unamuno: 18941897. Revista de Occidente, $2^{\text {a }}$ ép., año. IV, no 41, pp. 166184, 1966.

Cacho Viu, V. Repensar el noventa y ocho. Madrid: Biblioteca Nueva, 1997.

Calvo Carilla, J. L. La cara oculta del 98. Místicos e intelectuales en la España del fin de siglo (1895-1902). Madrid: Cátedra, 1998.

Díaz, E. Revisión de Unamuno. Análisis crítico de su pen- 
samiento político. Madrid: Tecnos, 1968.

Ereño Altuna, J. A. El pensamiento socialista de Unamuno en La lucha de clases (1894-1897). In: Chaguaceda Toledano, A. (ed.). Miguel de Unamuno. Estudios sobre su obra. III. Salamanca: Ediciones Universidad de Salamanca, 2008, pp. 99-127.

Fox, I. Unamuno y el nacionalismo: "En torno al casticismo" y la identidad nacional. In: Berchem, Th. y Laitenberger, H. (coords.). El joven Unamuno en su época. Actas del coloquio internacional Wurzburg 1995. Valladolid: Junta de Castilla y León-Consejería de Educación y Cultura, 1997, pp. 45-51.

García Blanco, M. Don Miguel y la universidad. Cuadernos de la Cátedra Miguel de Unamuno, vol. 13, pp. 13-32, 1963.

García Queipo De Llano, G. Los intelectuales y la dictadura de Primo de Rivera. Madrid: Alianza Editorial, 1988.

Gómez de la Torre, I. B. Unamuno y la Universidad: rector e intelectual. In: Flórez Miguel, C. (Coord.). Tu mano es mi destino. Salamanca: Ediciones Universidad de Salamanca, 2000, pp. 21-28.

Luján Palma, E. Unamuno y el pensamiento liberal: los inicios de una larga y peculiar relación. In: Chaguaceda Toledano, A. (ed.). Miguel de Unamuno. Estudios sobre su obra. IV. Salamanca: Ediciones Universidad de Salamanca, 2009, pp. 253-274.

Morón Arroyo, C. "Alma nacional": el trasfondo sociológico de "En torno al casticismo". In: Berchem, Th., y Lai- 
tenberger, H. (coords.). El joven Unamuno en su época. Actas del coloquio internacional Wurzburg 1995. Valladolid: Junta de Castilla y León-Consejería de Educación y cultura, 1997, pp. 11-29.

. Hacia el sistema de Unamuno. Palencia: Ediciones Calamo, 2003.

Orringer, N. Unamuno y los Protestantes Liberales (1902). Sobre las Fuentes de "Del sentimiento trágico de la vida”. Madrid: Editorial Gredos, 1985.

Ouimette, V. Unamuno y la tradición liberal española. In: Gómez Molleda, M. ${ }^{\mathrm{a}}$ D. (ed.). Actas del Congreso Internacional del Cincuentenario de Unamuno. Salamanca: Ediciones Universidad de Salamanca, 1989, pp. 69-80.

Pérez de la Dehesa, R. Política y sociedad en el primer Unamuno (1894-1904). Barcelona: Ediciones Ariel, 1973.

Raut, F., Mi defensa o el borrador de una contestación inédita a la tentativa de destitución de Unamuno del rectorado de Salamanca por el obispo Cámara (finales de 1903 principios de 1904). Cuadernos de la Cátedra Miguel de Unamuno, vol. 39, pp. 13-25, 2004.

Regalado García, A. El siervo y el señor. La dialéctica agónica de Miguel de Unamuno. Madrid: Editorial Gredos, 1968.

Ribbans, G. Unamuno en 1899: su separación definitiva de la ideología progresista. Cuadernos de la Cátedra Miguel de Unamuno, vol. 12, pp. 15-30, 1962.

Rivero Gómez, M. A. Desarrollo político en el joven 
Unamuno. Antecedentes de su etapa socialista. In: Chaguaceda Toledano, A. (ed.). Miguel de Unamuno. Estudios sobre su obra. III. Salamanca: Ediciones Universidad de Salamanca, 2008, pp. 165-179.

Roberts, S. Miguel de Unamuno y su relación con el socialismo entre 1914-1924: una primera aproximación. Cuadernos de la Cátedra Miguel de Unamuno, vol. 43, n. ${ }^{\circ}$ 1, pp. 89-98, 2007a.

- Miguel de Unamuno o la creación del intelectual español moderno. Salamanca: Ediciones Universidad de Salamanca, 2007b.

Salcedo, E. Vida de don Miguel: Unamuno, un hombre en lucha con su leyenda. Salamanca: Globalia Ediciones Anthema, 2005.

Urrutia León, M. M. Evolución del pensamiento político de Unamuno. Bilbao: Universidad de Deusto, 1997. 